\title{
Investigating the effectiveness of washing cantaloupe melon rind in preventing the transference of surface E. coli into melon flesh
}

\author{
Adam Chan ${ }^{1}$, and Helen Heacock ${ }^{2}$ \\ 1 Lead Author, B. Tech. Student, School of Health Sciences, British Columbia Institute of Technology, 3700 Willingdon Ave, Burnaby, BC V5G 3H2 \\ 2 Supervisor, School of Heath Sciences, British Columbia Institute of Technology, 3700 Willingdon Ave, Burnaby, BC V5G 3H2
}

\begin{abstract}
Cantaloupe melon was the source of a lethal outbreak of Listeria in 2011. This research investigated whether washing a contaminated cantaloupe rind was sufficient in preventing the transferring of Escherichia coli. Hence, the null hypothesis for this study was that there is no association between washing a contaminated cantaloupe melon and the presence of the contamination in the flesh. In this study, 10 cantaloupes were used to produce a sample size of 20 per washed and unwashed treatments. Each of the samples was transferred to EC broth to determine the presence and absence of Escherichia coli (E. coli), the indicator organism that acted as the "outbreak contaminant." The results showed $100 \%$ of the unwashed melons and $80 \%$ of the washed melons to have E. coli transferred into the flesh. A Chi Square analysis produced a p-value of 0.035. The study determined that there was a statistically significant association between washing a melon and the presence of E. coli in the melon flesh. The author recommends washing melon rind as a means to prevent foodborne illness caused by surface contaminants.
\end{abstract}

Key Words: Cantaloupe, melon, rind, flesh, outbreak, Escherichia coli, foodborne illness

\section{Introduction}

The reason for this study is from an actual Listeria outbreak in cantaloupes in 2011. The outbreak was traced back to a farm in Colorado and it was determined that the contamination was from Listeria in the environment. This is relevant to public health because there are possible consumers who do not wash their melons and just cut into the fruits. The contamination from Listeria under this circumstance was not common, but may occur again. The ability of pathogenic and spoilage-causing bacteria to adhere to surfaces of melons does not only present a food safety problem, it also causes economic loss to the produce industry (Ukuku \& Sapers, 2006a).

According to an article from the CFIA (2012), cantaloupe is one of the five commodities which have contributed to increased produce-associated foodborne disease outbreaks from 1998-2006. Hence, another reason for cantaloupe to be chosen is because this fresh produce is consumed raw and not subjected to a kill step during processing. Once these melons are available to the public, consumers become the last line of defence. This research will investigate if consumers are able to clean their melons before they cut into them, given that these melons are potentially contaminated.

\section{Literature Review}

\section{Legislation}

Under the Canada Agricultural Products Act, the Fresh Fruit and Vegetable Regulations regulate cantaloupes. The legislation regulates the grade and standards, as well as general tolerances, which apply to cantaloupe varieties originating from Cucum's melo vat. Cantalupensis. The only acceptable grade for cantaloupe is Canada No. 1 (Fresh Fruit and Vegetable Regulation, 2013). The standard requires that the melon be "fairly clean, mature and sound" and free of any physical damages. As defined by the Canadian Food Inspection Agency (2011), fairly clean refers to the melon when it does not show any noticeable dirt or foreign material that affects it appearance. In addition, under section 30 of the Regulation, it states that Canada No. 1 graded cantaloupes shall "be free from insects, insect larvae, insect damage and disease."

\section{Mode of microbial contamination to cantaloupes}

The predominant class of organisms on cantaloupe melon is aerobic mesophilic bacteria followed by lactic acid bacteria, Gram-negative bacteria, yeasts and moulds, and Pseudomonas spp. (Ukuku \& Fett, 2002). The rind of a cantaloupe provides a perfect surface for microorganisms to attach to. The external surface is characterized by a 
net comprising porous lenticel tissue (Webster \& Craig, 1976). Merriam-Webster (2013) defines lenticel tissues as "a loose aggregation of cells which penetrates the surface of a woody plan... where gases are exchange between the atmosphere and the underlying tissue." This material provides attachment sites for microorganisms and also a shield for the attached cells when the surface is cleaned (Ukuku \& Sapers, 2006b).

\section{Sources of contamination}

Cantaloupes can be contaminated during their growth, harvesting, processing, transportation, or preparation, if not handled properly by the food handler (CFIA, 2012). Many of the common sources of contamination are illustrated in Figure 1, below.

Preharvest contamination of melons with human pathogens may be the result from the use of sewagecontaminated irrigation water (FDA, 2003). Irrigation water, transported over long distances and distributed to farms through open and unprotected aqueducts, may become contaminated by surrounding activities (FDA, 2003). Other possible sources of contamination may originate from the feces of birds, reptiles, and other wildlife in the area (Clark \& McLean, 2003).

Post harvest contamination is one common source of contamination for melons. There have been incidences of cantaloupe melons where they have been found to have an increased concentration of indicator organisms on the melons during washing. Gagliardi et al. (2003) attributed the contamination to the management of primary wash tanks, such as the use of contaminated river water; build up of soils in tanks, and the depletion of chlorine. Ukuku \& Sapers (2006c) have observed melon processing operations in which cantaloupes were packed too tightly in wash tanks containing chlorinated water. The tight packing minimizes any opportunity for agitation of the melons or mixing of water. Additional sources of post harvest contamination include poor personal hygiene or work practices and inadequate plant sanitation (Ukuku \& Sapers, 2006c). Inadequately sanitized conveyor systems may permit debris to accumulate and microbial populations to build up on food contact surfaces; therefore, it is important to sanitize equipments on a regular schedule with sufficient frequency (Ukuku \& Sapers, 2006c).

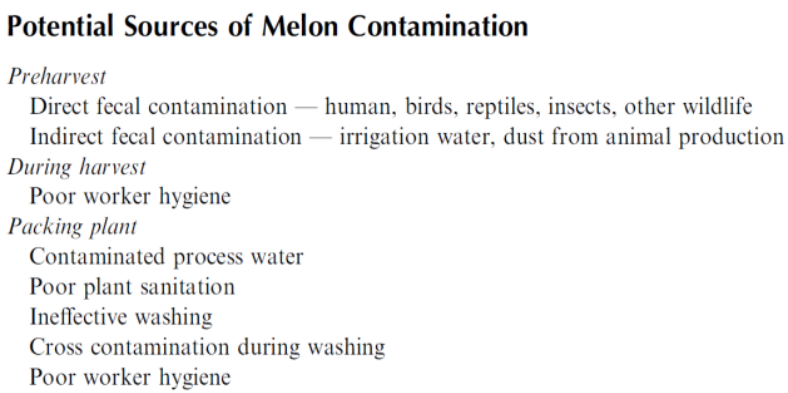

Figure 1.Summary for Sources of Contamination, Adapted from Ukuku \& Sapers (2006)

\section{Transfer of bacteria from rind to flesh}

A crucial part of this research is to determine whether microorganisms are actually able to be transferred from the rind and into the flesh. In fact, there are past data that justify this scenario. Ukuku and Sapers (2001) and Ukuku and Fett (2002) inoculated cantaloupe with Salmonella and Listeria, respectively. The reports showed that the survival and transfer of the pathogens were positive and the population on fresh-cut pieces also survived and increased during temperature abused conditions.

\section{Ability to support growth}

After being contaminated, the ability of the cantaloupe rind to support growth of the pathogens must be considered. The survival of such pathogens will permit them to proliferate to a concentration that is harmful to human health. Melon flesh is able to support the growth and survival of human pathogens, which include Salmonella, E. coli O157:H7, and Listeria monocytogenes (Ukuku \& Sapers, 2006c).

Del-Rosario and Beuchat (1995) investigated the ability of $E$. coli $O 157: H 7$ to survive and grow on the flesh and external rind surface of cantaloupe melons. In their study they found that the pathogen was able to survive and proliferate at $25^{\circ} \mathrm{C}$ on the melon flesh, during a 34 hour storage period. However, the concentration of the pathogen on the melon flesh (inside of the melon) remained constant at $5^{\circ} \mathrm{C}$ during the same time period. In another test, they observed the rind of cantaloupes and found that the growth of the pathogen was also present at $25^{\circ} \mathrm{C}$ for $14-22$ days. The major difference in this version of the test was that the pathogen rapidly died on the rind surface (outside surface of the melon) when it was stored at $5^{\circ} \mathrm{C}$.

In a research conducted by Golden et al. (1993), the ability of Salmonella spp. to grow on rind-free pieces of melons was studied. They tested cantaloupe, watermelon and honeydew, with $\mathrm{pH}$ values that ranged from $5.90-6.67$. In another study, Nyguyen et al. (2012) from the University of Florida found the 
$\mathrm{pH}$ of fresh cut cantaloupe to be 7.01. The FDA food code considers the cantaloupe as a potentially hazardous food because it is capable of supporting the growth of pathogens due to its $\mathrm{pH}$ being 5.2-6.7 and high water activity between 0.97 and 0.99 . The near neutral $\mathrm{pH}$ of the inner flesh and availability of nutrients heightened the survival of pathogens in cantaloupe (Richards and Beuchat, 2004). Consequently, the results from Golden et al. (1993) indicated that Salmonella growth was rapid and prolific on the melons at $23^{\circ} \mathrm{C}$. Similar to the study by Del-Rosario and Beuchat (1995), the Salmonella population did not increase during the 24 hour incubation at $5^{\circ} \mathrm{C}$.

Further evidence provided by Bhagwat (2006) supports the fact that the transfer of bacteria from the rind to edible melon flesh can occur. Salmonella spp. and $E$. coli $\mathrm{O} 157: \mathrm{H} 7$ are able to proliferate to hazardous levels on cut melons stored at ambient temperature.

\section{Control measures}

When the rind of cantaloupe melons is contaminated, it becomes difficult to clean because of the rough netted surface. This characteristic of the rind provides areas for bacterial attachment and protection from cleaning and sanitization (CFIA, 2012). In a comparison study done by Park and Beuchat (1999) they reported that greater numbers of E. coli and Salmonella cells were deactivated or removed from inoculated honeydew melon than from cantaloupe when the melons were washed with sanitizer solutions. When 200-2000ppm chlorine solution was used, the microorganisms found on honeydew melon were reduced to lower levels than the population on cantaloupes (Park \& Beuchat, 1999). From these results, it seems like chlorine solution may be an option to effectively disinfect store bought cantaloupes that may have been subject to contamination.

Due to the difficulty of supplying adequate water to mobile washing equipment, field-packed melons are generally not washed. The melons that are transferred to packing plants may be immersed in a wash tank. It has been found by Gagliardi et al. (2003) that this method had minimal or no reduction and in some cases, an increase in microbial populations on cantaloupes and honeydew melons.

The effectiveness of other disinfectants such as chlorinated water and lactic acid were tested in a study done by Materon (2003). In this experiment, he inoculated cantaloupes with $E$. coli $\mathrm{O} 157: \mathrm{H} 7$ and immersed the melons in disinfectants to decontaminate the melon. However, the results were similar to Park and Beuchat where bacterial cells were reduced, but not eliminated. Materon concludes by stating "The development of sanitizers more effective than chlorine for total elimination of this pathogen from the surface of cantaloupes is needed."

Hot water is another method used for decontamination of whole cantaloupes. This method may be more practical for consumers because this resource is more easily accessible than commercial sanitizers. This method was able to significantly reduce microbiological populations on melon surfaces. The major advantage, which is also the focus of this research, was that it reduced the probability of potential transfer of pathogenic bacteria from the rind to the flesh during cutting (Ukuku et al., 2004). According to Bhagwhat (2006), the most efficient method to remove microbes from the surfaces of melons was to scrub the surface with a clean brush under running water.

\section{EHO's Involvement}

Health inspectors play a general role in the food safety aspect of fresh fruits, such as cantaloupes. An inspector has the role of ensuring the safety of all food that is sold and distributed through food premises (Manitoba Health, 2013). Any location or facility where food is prepared, stored or served to the general public is considered a food handling establishment (Manitoba Health, 2013). Some examples may include restaurants, grocery stores, and catering facilities; therefore, health inspectors have an important role in educating food handlers and consumers about safe food handling practices, such as removing surface contamination of fruits and vegetables (Fraser Health, 2011).

\section{Methods}

An E.coli culture was enriched in TSA broth to prepare for the study. Over a 24 hour period at $35^{\circ} \mathrm{C}$, the bacterial culture was enumerated to $10^{9} \mathrm{cfu} / \mathrm{mL}$. Serial dilution was prepared by using a bottle filled with $99 \mathrm{ml}$ of tap water. With this blank, the E. coli concentration was diluted to $10^{7} \mathrm{cfu} / \mathrm{mL}$. The diluted E.coli was further diluted in a bag, filled with $495 \mathrm{~mL}$ of tap water, to a concentration of $10^{5} \mathrm{cfu} / \mathrm{mL}$. A negative control for the tap water and a positive control for the E. coli broth were plated.

Each whole cantaloupe melon was immersed into bags containing $500 \mathrm{~mL}$ of diluted "spiked" solution for five minutes. These melons were allowed to air 
dry for 30 minutes at room temperature. Following the drying procedure, half of the melons were washed with hot running water and a scrubbing brush while the other half were left for cutting, without washing. The washed melons were allowed an additional 30 minutes for air drying.

Each of the melons were separated into quarters where $25 \mathrm{~g}$ samples were drawn and transferred to individual stomacher bag where each sample was incubated at $35^{\circ} \mathrm{C}$ for 24 hours. From each bag, $1 \mathrm{~mL}$ samples were transferred to EC broth tubes for standard fecal coliform testing. The procedure is summarized in Figure 2.

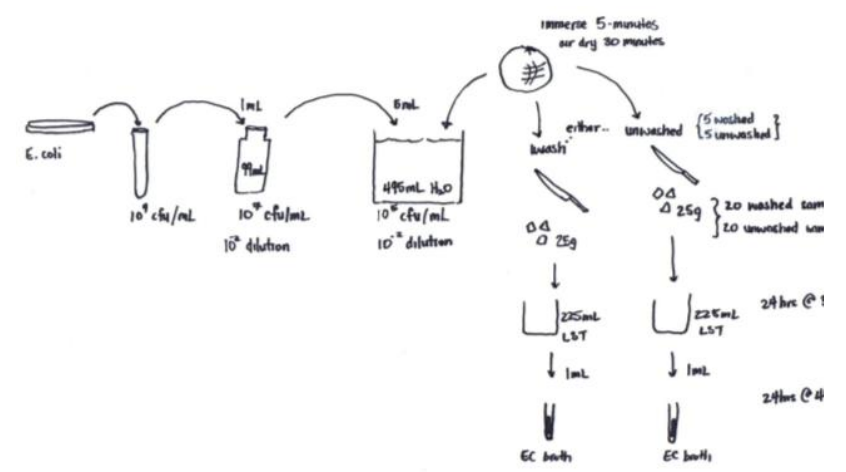

Figure 2: Flow diagram of procedure

\section{Results}

\section{Description of data}

The data collected from this study were counts of absence and presence of E. coli in melon flesh. This data was considered nominal and dichotomous, since the only two options were either present or absent (ENVH 8400 notes, 2013). The data originated from two sets of cantaloupes, each with a sample size of 20 . The data represented the proportion of washed cantaloupes that contained contamination and the proportion of unwashed cantaloupes that contained contamination.

\section{Descriptive statistics}

As in figure 3,20/20 unwashed samples showed the presence of E. coli, whereas, in the washed samples 16/20 indicated presence.

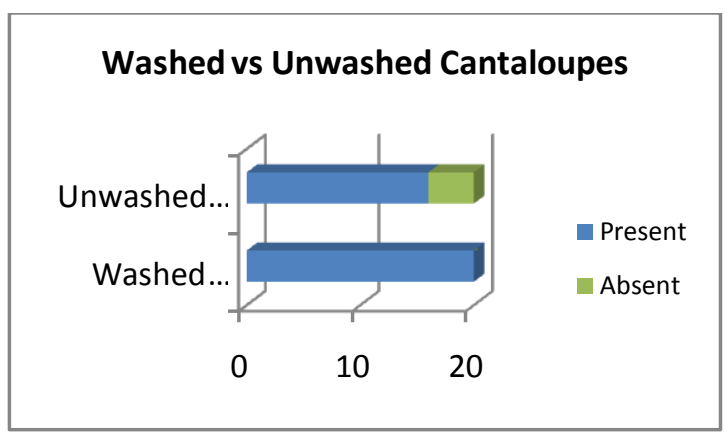

Figure 3: A Comparison of Washed and Unwashed Cantaloupes

\section{Inferential statistics}

A chi-squared test was used to analyze the data collected from this study. This type of test is used to determine "... whether there is a difference in proportions of outcomes in two or more groups or whether there is an association between two or more groups" (ENVH 8400 notes, 2013). The test is only used on nominal data.

Hence, the null hypothesis for this study was that there is no association between washing a contaminated cantaloupe melon and the presence of the contamination in the flesh. Conversely, the alternative hypothesis stated that there is an association between washing a contaminated cantaloupe melon and the presence of the contamination in the flesh.

\section{Interpretation}

The nominal data qualify as nonparametric as the testing of the hypothesis did not require normal distribution or variance assumptions about the populations from which the samples were drawn (Key, 1997).

Looking at the Pearson's Chi Square test, the pvalue was 0.035 ; therefore, the null hypothesis was rejected at $\alpha=0.05$ and it was concluded that washing melon rinds appears to reduce bacterial load on the rinds of cantaloupes. Based on that, there is an association between washing a melon and the presence of E. coli in the melon flesh (NCSS, 2013). However, because the p-value was not very low there is a chance of an alpha error. If an alpha error were to exist, the rejection of the null hypothesis would be incorrect and that there was, in fact, no association between washing of contaminated melons and the presence of contamination. No power was given in this test. 


\section{Discussion}

\section{Significance of results}

The results from this research have shown that washing a cantaloupe rind that was contaminated is sufficient to prevent the transferring of the bacteria from the rind to the flesh. In order to show that the bacteria were able to transfer from the rind to flesh when it the melon was cut, a positive control was used where the melon was inoculated and not washed. With these findings, a further discussion can be made from the results.

\section{Comparison to literature reviews}

The CFIA (2012) mentioned that the characteristic of the rind provides areas for bacterial attachment and protection from cleaning and sanitization. This challenge was the reason why the data in the "washed" column showed many melons that had the presence of the bacteria even after being washed.

Similar to Ukuku and Sapers (2001) who found that the survival and transfer of Salmonella was positive on fresh cut pieces of melon, the author from this study found that E.coli was also able to transfer from the rind to the flesh of the melons.

Researchers, Ukuku et al. (2004) and Bhagwhat (2006), have found that the use of hot water and the mechanical movement of a brush under running water were effective ways to reduce the bacterial load on contaminated melon rinds. This method was replicated in the procedure of this study and showed that E.coli was successfully removed from the rind of the cantaloupes. The removal was justified by negative results in the EC broth tubes that tested for the presence and absence of fecal coliforms.

\section{Potential errors}

A systematic error may have occurred during the cutting and transferring of melon flesh into stomacher bags. Due to time constraint and lab space availability, the experiment was done in a small area on a lab bench. There was a possibility for crosscontamination in the workspace, although precautions were taken to reduce the chances of any contamination. Some precautions included separating washed and unwashed melons, washing hands frequently, and sterilizing equipment as often as necessary.

\section{Alpha and beta}

An alpha error is considered if the p-value falls in between 0.05 and 0.01 . The $\mathrm{p}$-value in this study was
0.035. In order to minimize the possible alpha error, the cut-off of alpha could be set at 0.01 . If alpha was set as 0.01 , then the null hypothesis would not have been rejected when the p-value was 0.035 . A beta error may be present as a result when the p-value is insignificant and is close to the cut-off. In this alternate scenario, the number of samples will need to be increased in order to reduce beta error.

\section{Contribution of findings}

The purpose of the study was to determine if $E$. coli is transferred into cantaloupe melon flesh when it is cut. The finding from this study raised awareness in regards to the importance of washing melon rinds and the direct role consumers have in preventing a foodborne illness.

\section{Recommendations}

\section{Results}

Based on these findings, it is recommended that cantaloupe melons are washed before they are cut for human consumption. There was statistical significance from the data that supported the washing of melon to prevent further contamination. In fact, it is difficult to determine whether a melon rind is contaminated or not until an actual outbreak occurs or if someone falls ill. The best method of prevention is to clean the melon rinds.

However, if an outbreak was present then regular cleaning may not be sufficient to prevent further pathogenic transfer from the rind to the flesh. The reason is because this study was not able to determine the actual amount of bacteria that was transferred. So it is difficult to conclude if washing was effective in removing or reducing the pathogen to safe enough levels to consume. As well, some pathogens may have a low infectious dose and cleaning may not necessarily remove all pathogens.

\section{Limitations}

\section{Media}

The EC medium used was designed to test for the presence of fecal coliforms, but not $E$. coli specifically. If budget had permitted, VRBA with MUG or EC medium with MUG would have been a better medium to use. These media specifically test for $E$. coli and the agar allows for enumeration. 


\section{Quantitative vs. Qualitative}

A qualitative measure can only measure the presence and absence of the fecal coliform that transfers on to the flesh. It is a limitation of this study because it cannot quantify the amount of $E$. coli that was transferred. The LST broth used in this study enriches any amount of bacteria that was transferred on to the melon flesh; therefore, even if the concentration on the melon flesh was insufficient to cause a foodborne illness, the results would have still shown a positive for $E$. coli. The qualitative results can only be used to conclude whether washing was effective in preventing the transfer of $E$. coli into melon flesh when it is cut.

\section{Sample Size}

Instead of using individual melons as one sample, the author had to divide each melon into four subsamples due to budget constraints. Each sub-sample counted as one sample in the experiment. The problem was that if one rind was contaminated it would then be highly likely for the other quarters to be contaminated from the same knife blade cutting through. To reduce the chance of this occurring, the knives were sterilized with 70\% isopropyl alcohol and flamed before each cut was made into the melon.

In addition, another problem with the sample size was the amount of melon that was collected from each quarter. The amount of $25 \mathrm{~g}$ may not necessarily be representative of the entire sample that was much larger than $25 \mathrm{~g}$.

\section{Fisher's Exact Test}

With expected values of $\leq 2$ in two cells, the Fisher's exact results could be read. In this case, the P-value would become 0.106 and therefore not statistically significant. Increasing the sample size would confirm these findings.

\section{Future research}

For future studies, the author recommends doing a quantitative analysis to determine whether a sufficient concentration of potential pathogens is transferred from the rind into the melon flesh to cause illness. As mentioned in the limitations, a quantitative measure would give a better representation of the effectiveness of washing the rind.

\section{Conclusions}

The purpose of this research was to perform a presence and absence test to determine if inoculated $E$. coli is transferred into cantaloupe melon flesh when it is cut, by comparing washed and unwashed contaminated melons. The null hypothesis for this study was that there is no association between washing a contaminated cantaloupe melon and the presence of the contamination in the flesh.

In this study, the author was able to reject the null hypothesis and conclude that there was an association between washing a melon and the presence of $\mathrm{E}$. coli in the melon flesh. The results have shown that washing is effective in preventing the presence of $\mathrm{E}$. coli due to a transfer from a contaminated rind. The role of an Environmental Health Officer may include educating the public in properly storing and cleaning melons before they are consumed.

\section{Acknowledgements}

The completion of this document and research was made possible through the financial contribution from the British Columbia Institute of Technology.

Additional thanks are given to Helen Heacock and Bobby Sidhu for their comments and editing as well as Ken Keilbart and Melinda Lee for laboratory assistance and support.

\section{Competing interests}

The author declares that they have no competing interests in the completion of this research.

\section{References}

Bhagwat, A.A. (2006) Microbiology of fresh produce. Microbiological safety of fresh-cut produce: Where are we now? Washington, DC.

Canadian Food Inspection Agency (CFIA). (2012) 2009-2010 Bacterial pathogens in cantaloupes in the Canadian market. Retrieved from : http://www.inspection.gc.ca/food/chemicalresiduesmicrobiology/microbiology/cantaloupes/eng/13485 $\underline{\text { 92270745/1348592434455 }}$ 
Canadian Food Inspection Agency (CFIA). (2011)

Fruit Inspection Manuals. Cantaloupes. Retrieved from: http://www.inspection.gc.ca/food/freshfruits-and-vegetables/quality-inspection/fruitinspection-

manuals/cantaloupes/eng/1303677550990/1303677 $\underline{635989}$

Clark, L., \& McLean, R.G. (2003) A review of pathogens of agricultural and human health interest found in blackbirds, in Management of North American Blackbirds, Linz, G.M., Ed., National Wildlife Research Center, Fort Collins,p. 103.

Del-Rosario, B.A., \& Beuchat, L.R. (1995) Survival and growth of enterohemorrhagic Echerchia coli O157:H7 in cantaloupe and watermelon. Journal of Food Protection, 58(1), 105-107

ENVH 8400 Class notes (2013) Inferential statistics.

Fresh Fruit and Vegetable Regulations, C.R.C., c. 285 (2013) retrieved from: http://lawslois.justice.gc.ca/PDF/C.R.C.,_c. 285.pdf

Gagliardi, J.V., Millner, P.D., \& Ingram, D. (2003) On-farm and postharvest processing sources of bacterial contamination to melon rinds.

Environmental Sciences \& Pollution Management, 66(1), 82-87

Golden, D.A., Rhodehamel, E.J., \& Kautter, D.A. (1993) Growth of Salmonella spp. in cantaloupe, watermelon, and honeydew melons. Journal of Food Protection, 56, 194-196

Health Canada (2012) Health Canada's guidelines for Canadian drinking water quality. Retreived from: http://www.hc-sc.gc.ca/ewh-semt/pubs/watereau/coliforms-coliformes/index-eng.php

Key, J. (1997) Oklahoma State University. Chis square. Retrieved from: http://www.okstate.edu/ag/agedcm $4 \mathrm{~h} /$ academic/age d5980a/5980/newpage28.htm

Materon, L.A. (2003) Survival of Escherichia coli O157:H7 applied to cantaloupes and the effectiveness of chlorinated water and lactic acid as disinfectants. World Journal of Microbiology \& Biotechnology, 19(8), 867-873
Merriam-Webster Dictionary. (2013) Lenticel.

Retrieved from: http://www.merriam-

webster.com/dictionary/lenticel

Nguyen, T.P., Danyluk, M.D., Schneider, K.R. (2012) Growth, reduction, and survival of bacteria on melon types. Retrieved from: http://edis.ifas.ufl.edu/fs191

NCSS (2013) NCSS 9 Statistical software.

Nguyen, T.P., Danyluk, M.D., Schneider, K.R. (2012)

Growth, reduction, and survival of bacteria on melon types. Retrieved from:

http://edis.ifas.ufl.edu/fs191

Park, C.M., \& Beuchat, L.R. (1999) Evaluation of sanitizers for killing Escherichia coli O157:H7, Salmonella, and naturally occurring microorganisms on cantaloupes, honeydew melons, and asparagus. Dairy, Food and Enviromental. Sanitation, 19, 842

Richards, G. M., \& L. R. Beuchat. (2004). Attachment of Salmonelia Poona to cantaloupe rind and stem scar tissues as affected by temperature of fruit and inoculum. Journal of Food Protection 67 (7), 1359-1364

Ukuku, D.O., \& Fett, W. (2002) Behavior of Listeria monocytogenes inoculated on cantaloupe surfaces and efficacy of washing treatments to reduce transfer from rind to fresh-cut pieces. Journal of Food Protection, 65(6), 924-930

Ukuku, D.O., \& Fett, W.F. (2002) Effectiveness of chlorine and nisin-EDTA treatments of whole melons and fresh-cut pieces for reducing native microflora and extending shelf-life, Journal of Food Safety, 22(4), 231-253

Ukuku, D.O., \& Sapers, G.M. (2001) Effect of sanitizer treatments on Salmonella Stanley attached to the surface of cantaloupe and cell transfer to fresh-cut tissues during cutting practices. Journal of Food Protection, 64(9), 1286-1291

Ukuku, D.O., \& Sapers, G.M. (2006a) Microbiological safety issues of fresh melons. Mocroflora of melons. Taylor and Francis Group, LLC

Ukuku, D.O., \& Sapers, G.M. (2006b) Microbiological safety issues of fresh melons. Efficacy of conventional washing. Taylor and Francis Group, LLC 
Ukuku, D.O., \& Sapers, G.M. (2006c)

Microbiological safety issues of fresh melons.

Issues with fresh cut melons. Taylor and Francis Group, LLC

Ukuku, D.O., Pilizota, V., \& Sapers, G.M. (2004)

Effect of hot water and hydrogen peroxide treatments on survival of Salmonella and microbial quality whole and fresh-cut cantaloupes. Journal of Food Protection., 67(3), 432-437

US Food and Drug Administration (FDA) (2003)

Detention without physical examination of cantaloupes from Mexico. Retrieved from: www.fda.gov.ora/fiars/ora import ia2201.html

Webster, B.D., \& Craig, M.E. (1976) Net

morphogenesis and characteristics of the surface of muskmelon fruit. Journal of the American Society for Horticultural Science, 101, 412 